Article ID: 563

DOI: 10.5586/am.563

Publication History

Received: 2020-06-05

Accepted: 2020-11-14

Published: 2021-04-22

Handling Editor

Małgorzata

Ruszkiewicz-Michalska; Institute

for Agricultural and Forest

Environment, Polish Academy of

Sciences; University of Łódź,

Poland; https://orcid.org/0000-

0001-8901-0552

Authors' Contributions SAS and SD devised the initial

idea of the project; UR

developed the research

concept, collected the data, and

performed the molecular and

phylogenetic analyses; the

authors have contributed

equally to the writing of the

manuscript

Funding

The study was supported by the

Paris Lodron University of

Salzburg; the plant was a gift

from the Palmengarten

Frankfurt to the Botanical

Garden Salzburg.

Competing Interests

No competing interests have

been declared.

\section{Copyright Notice}

() The Author(s) 2021. This is an open access article distributed under the terms of the Creative Commons Attribution License, which permits redistribution, commercial and noncommercial, provided that the article is properly cited.

\title{
Unexpected Occurrence of Cladosporium spp. on the Inner Surface of the Spathe of the Titan Arum, Amorphophallus titanum
}

\author{
Ulrike Ruprecht (1D ${ }^{1 *}$, Stephanie A. Socher (1) ${ }^{1,2}$, Stefan Dötterl (1) ${ }^{1,2}$ \\ ${ }^{1}$ Paris Lodron Universität Salzburg, Fachbereich Biowissenschaften, Hellbrunnerstrasse 34, \\ 5020 Salzburg, Austria \\ ${ }^{2}$ Paris Lodron Universität Salzburg, Fachbereich Biowissenschaften, Botanischer Garten, \\ Hellbrunnerstrasse 34, 5020 Salzburg, Austria \\ * To whom correspondence should be addressed. Email: ulrike.ruprecht@sbg.ac.at
}

\begin{abstract}
The air-borne distributed genus Cladosporium Link is globally one of the most common fungal genera. By sequencing the barcode marker ITS, here, we document two taxa belonging to this genus - C. cf. dominicanum Zalar, de Hoog \& Gunde-Cimerman and C. halotolerans Zalar, de Hoog \& Gunde-Cimerman (C. sphaerospermum Penz complex) - which were detected on the inner surface of the spathe of the titan arum, Amorphophallus titanum (Becc.) Becc. (Araceae). Titan arum holds the record for the largest unbranched inflorescence in the plant kingdom, with a height reaching up to 3 meters. The two identified Cladosporium species are part of a clearly defined fungal layer inside the proximal region of the spathe, surrounding the flower-containing region of the spadix. To the best of our knowledge, this is the first record of a macroscopically visible layer of Cladosporium on a living plant material. Furthermore, this study also discusses why this layer occurs only in a spatially restricted region of the spathe, and the possible consequences that the occurrence of these fungi might have on the development and reproduction of the plant.
\end{abstract}

\section{Keywords}

plant-associated fungi; fungal layer; largest unbranched inflorescence

\section{Introduction}

Plant-associated fungi are ubiquitous and have been studied extensively. They are members of highly diverse microbial communities (bacteria, archeae, actinomycetes, protists, and viruses) that play a crucial role in plant growth and fitness (Hardoim et al., 2015; Stępniewska \& Kuźniar, 2013). In several instances, plants benefit from the associated microbiome, which either colonizes the plant surface (phyllosphere), the interior tissues (endophytes), or both (Wani et al., 2015). On the other hand, these fungi might exert negative effects on plant health, and several fungal species that adversely affect crop production have been identified (Latz et al., 2018).

Globally, the air-borne distributed genus Cladosporium Link, which inhabits diverse habitats, such as plants, animals, soils, humans, textiles, and environments with high osmotic stress, is one of the most common fungal genera (El-Morsy, 2000; Flessa et al., 2012; Zalar et al., 2007). Several species belonging to this genus are pathogenic and hyperparasitic, while others are common endophytes as well as phylloplane fungi. However, a majority of these fungi are saprobic molds, comprising some of the most common species of this genus, such as Cladosporium herbarum Pers. and C. sphaerospermum Penz (Bensch et al., 2012).

Titan arum, Amorphophallus titanum (Becc.) Becc. produces the largest unbranched inflorescence worldwide (Barthlott \& Lobin, 1998; Davis et al., 2008), with a length reaching up to 3 meters. The plant is monoecious and proterogynous, with female 


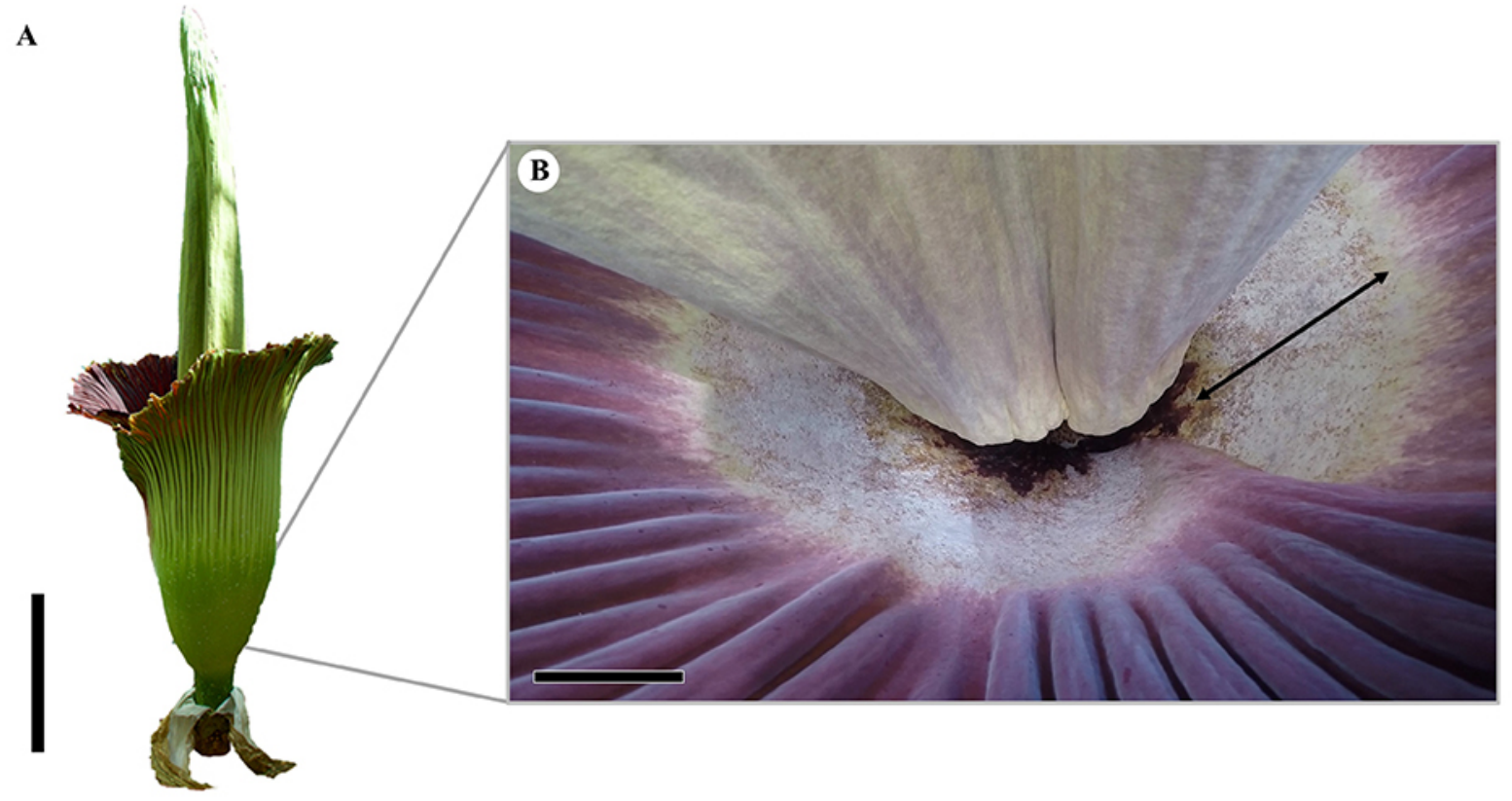

Figure 1 (A) Inflorescence of Amorphophallus titanum (day one of flowering, total height: $237 \mathrm{~cm}$ ) picture at the Faculty of Natural Sciences, Paris Lodron Universität Salzburg (June 2019); scale bar: $50 \mathrm{~cm}$. (B) Clearly defined fungal layer inside the proximal part of the spathe (black double-arrow, $15-20 \mathrm{~cm}$ ); scale bar: $10 \mathrm{~cm}$.

(pistillate) and male (staminate) flowers located at the basal part of the spadix. Half of the spadix length, including the flower-bearing region, is surrounded by a large green bract, the spathe. The distal part of the spathe opens during flowering, unveiling the purple, reddish color on its inner surface. In contrast, the proximal part is yellowish to brownish on its inner surface and remains closed at all times. Titan arum attracts its pollinators, such as beetles (Gandawijaja et al., 1983) by olfactory deceit. During the 2 days of flowering, the spadix releases an intense odor resembling that of a carcass to lure pollinators (Barthlott \& Lobin, 1998).

The aim of this study was to investigate by molecular methods, the unexpected, spatially well-defined fungal layer detected during anthesis inside the proximal part of the spathe of the specimen at the Paris Lodron Universität Salzburg (June 2019).

\section{Material and Methods}

The examined A. titanum individual flowered for 2 days in June 2019, at the Faculty of Natural Sciences (Paris Lodron Universität Salzburg). On day one of flowering, a small portion of the fungal layer was scraped off from the inner surface of the proximal part of the spathe, using a sterilized scalpel (Figure 1B and Figure 2). Altogether, four samples were collected. The DNA obtained from these samples was purified with the ZymoBIOMICs DNA Miniprep Kit (USA) as per the manufacturer's instructions. To amplify the internal transcribed spacer region of the nuclear ribosomal DNA (ITS), the standard fungal primers ITS1 and ITS4 (White et al., 1990) were used, in accordance with the protocol described by Ruprecht et al. (2020). Unpurified PCR products were dispatched to Eurofins Genomics (Germany) for sequencing from both ends.

The newly obtained sequences of the marker ITS were aligned with closely related sequences from GenBank to check for sequence homology and identification, according to the species concept of Bensch et al. (2012) and Zalar et al. (2007), which is capable of providing sequences based on morphological results. The phylogenetic analyses were performed according to the methodology outlined by Ruprecht et al. (2020). For the maximum likelihood analysis using the best-fit evolutionary model according to BIC, "K2P+I" was selected with the implemented model finder (Kalyaanamoorthy et al., 2017) on the IQ-TREE program (Trifinopoulos et al., 2016). Additionally, the Bayesian phylogeny (Ronquist \& Huelsenbeck, 2003) 

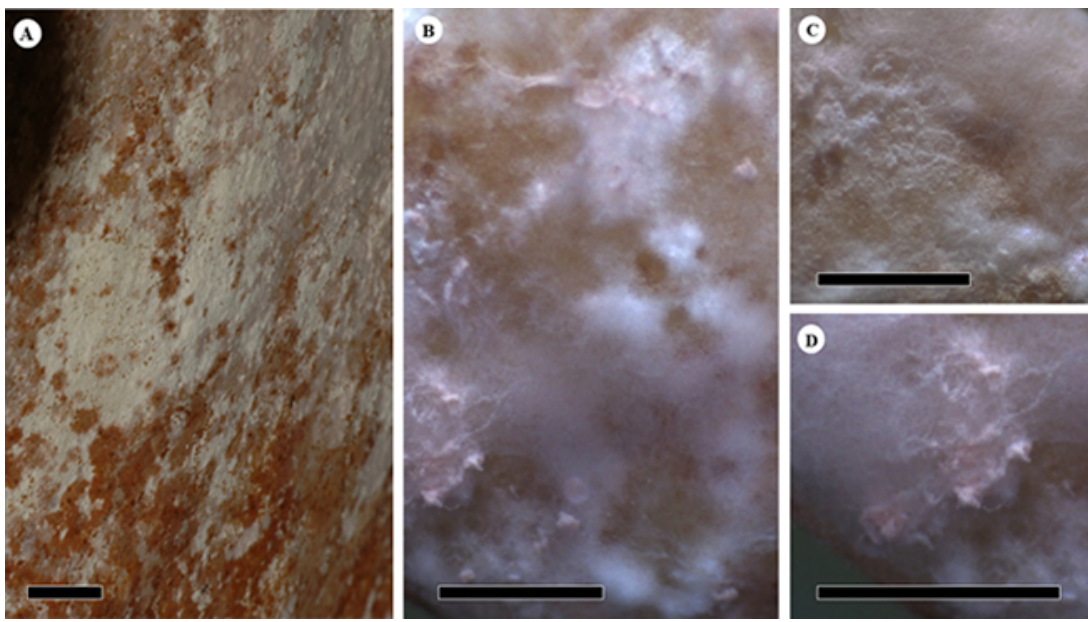

Figure 2 Fungus infested surface of the inside, proximal area on the spathe of Amorphophallus titanum. (A,B) Overview of the complete fungal community at different magnifications. (C) The enlarged area shows a darkly pigmented mycelium in the center. (D) A lighter, clouded fungal mycelium. Scale bars: (A) $10 \mathrm{~mm}$; (B-D) $1 \mathrm{~mm}$.

was calculated based on the 1-mio generations and the "burn in" of the $25 \%$ of the trees, resulting in a total of 750 trees. The phylogenies were midpoint rooted and visualized using the FigTree v1.4.3 software (Rambaut, 2014).

\section{Results and Discussion}

Altogether, four assembled sequences of Cladosporium spp. (ITS, GenBank acc. numbers: MT149222-MT149225; Table 1) were obtained from the inner surface of the spathe of the examined A. titanum. The sequences indicated the presence of two distinct species of the cosmopolitan and very common hyphomycete genus Cladosporium (Bensch et al., 2012). Two accessions (TW2 and TW4) were closely related to the well-supported species C. dominicanum Zalar, de Hoog \& Gunde-Cimerman. Moreover, the other two accessions (TW1 and TW3) were identical to those of $C$. halotolerans Zalar, de Hoog \& Gunde-Cimerman. These species are closely related to each other and, along with several other species, form the C. sphaerospermum complex (Figure 3) (Bensch et al., 2012; Zalar et al., 2007). Both $C$. dominicanum as well as $C$. halotolerans have similar habitat preferences, frequently occurring in hypersaline environments and on plant materials. Owing to

Table 1 Newly generated accessions of Cladosporium species and additional sequences from Genbank.

\begin{tabular}{lll}
\hline Species & $\begin{array}{l}\text { Uncultured strains/culture acc. } \\
\text { numbers }\end{array}$ & $\begin{array}{l}\text { GenBank acc. numbers, } \\
\text { ITS }\end{array}$ \\
\hline C. halotolerans & TW1 & MT149222 \\
C. cf. dominicanum & TW2 & MT149223 \\
C. halotolerans & TW3 & MT149224 \\
C. cf. dominicanum & TW4 & MT149225 \\
C. dominicanum & CBS 119415; EXF-732; dH 16386 & DQ780353 \\
C. fusiforme & CBS 119414; EXF-449; dH 16387 & DQ780388 \\
C. halotolerans & CBS 119416; EXF-572 & DQ780364 \\
C. langeronii & CBS 189.54 & DQ780379 \\
C. psychrotolerans & CBS 119412; EXF-391; dH 16390 & DQ780386 \\
C. salinae & CBS 119413; EXF-335; dH 16389 & DQ780374 \\
C. sphaerospermum & CBS 193.54; ATCC 11289; IMI 49637 & DQ780343 \\
C. velox & CBS 119417; CPC 11224; dH 16388 & DQ780361 \\
\hline
\end{tabular}




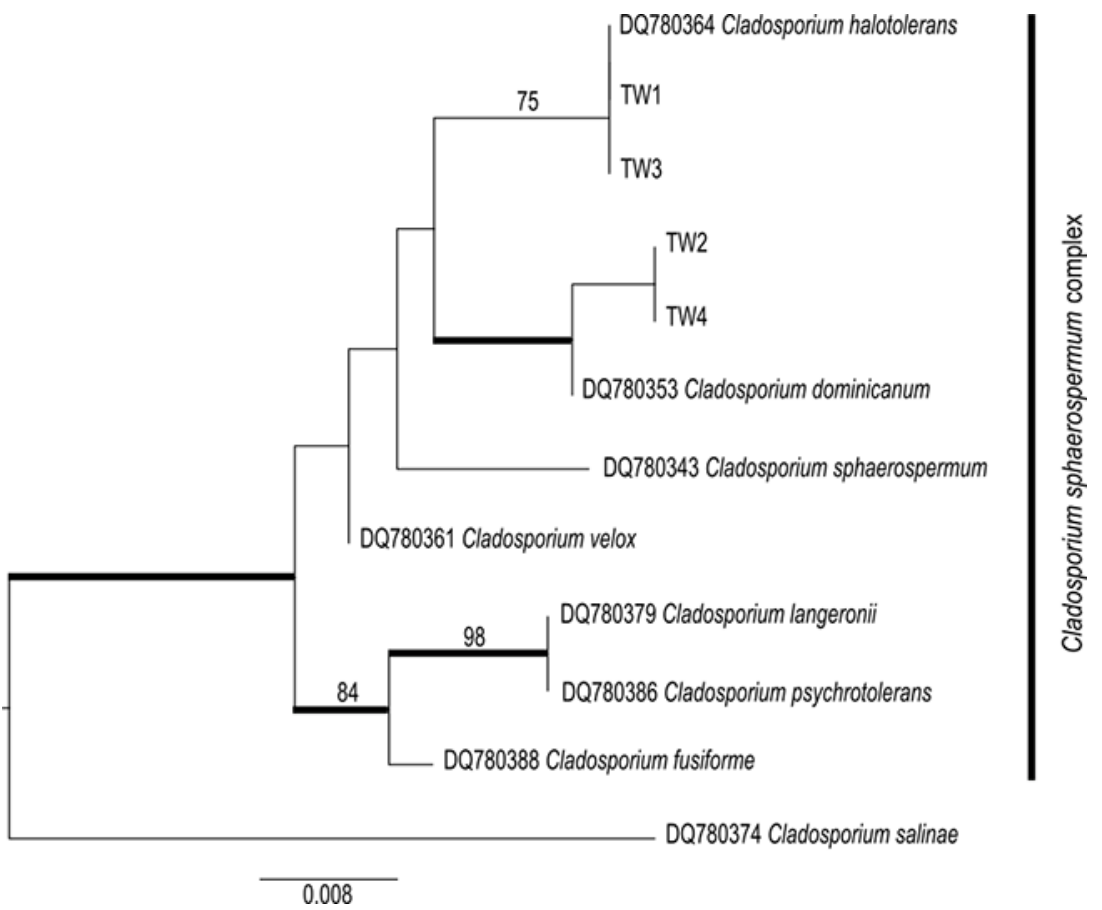

Figure 3 Phylogeny of the Cladosporium sphaerospermum complex using the accessions from this study, integrated with the species concept of Bensch et al. (2012) and Zalar et al. (2007). The bootstrap values with $\geq 75$ support of the maximum likelihood (ML) analyses and the posterior probability values of the Bayesian analyses with $\geq 0.95$ support (branches in bold) were mapped on the ML tree.

their air-borne distribution, they are also present on several other substrates, such as soils, textiles, and humans. Cladosporium dominicanum shows restricted proliferation in saline waters in (sub)tropical climates but has also been described as saprobic on fruit surfaces (Bensch et al., 2012). Sequences from the NCBI database identical to those of the investigated fungal strains (TW2 and TW4) have been isolated from different host plants primarily inhabiting warmer habitats worldwide. Cladosporium halotolerans is globally distributed and even occurs in Arctic habitats. The latter is distinguishable by a velvety gray olivaceous mycelium, in contrast to the brighter color of the remaining fungal layer (Figure 3) (Bensch et al., 2012; Zalar et al., 2007).

The well-developed fungal layer on the inner surface of the spathe on day one of flowering of A. titanum suggests that the hyphomycete layer originated during the development of the inflorescence. Moreover, a visible fungal layer (without any specific information on species identity) was spotted on the spathe to varying degrees (sporadic to completely covered) on other flowering individuals under cultivation (personal communication: Marianne Lauerer, Botanical Garden Bayreuth; Boris Schlumpberger, Herrenhäuser Gärten Hannover; Wolfgang Stuppy, Botanical Garden Bochum; Patrick Knopf, Botanical Garden Dortmund). To the best of our knowledge, none of the earlier studies have identified this fungus growing in the natural habitat of the plant, the rain forests of Sumatra.

A previous study conducted by Sayyad and Mulani (2016) on the closely related species Amorphophallus sylvaticus (Roxb.) Kunth indicated that Cladosporium is one of the several endophytic fungal genera that colonize the corm. Thus, Cladosporium is not only associated with A. titanum, but is also more widespread in the genus Amorphophallus Blume ex Decne. It is possible that the Cladosporium taxa recorded in the present work grow as endophytes in the form of A. titanum, and colonize the spathe during its development.

At this stage, it is not clear if the identified fungi are commensalistic, parasitic, mutualistic, or pathogenic interaction partners of A. titanum. However, based on all known collections of these species, they are unlikely to be parasitic and pathogenic. 
All previous strains referred to the isolation of saprobic samples (Bensch et al., 2012). In addition, although there seemed to be no effect on the flowering process, a negative influence on the success of pollination could exist. A slippery surface is one of the characteristics of the area where the fungal layer occurs, as is well known from trapping devices in Araceae (Bröderbauer et al., 2012). The cells in this area, but not in other areas of the spathe, are papillate and covered with epicuticular wax crystalloids (Bröderbauer et al., 2012; Napp-Zinn \& Scheferhoff, 1998). When overgrown by fungi, these cells may lose their ability to create a surface that is slippery for insects. Once inside the inflorescence and close to the flowers, potential pollinators may leave the inflorescence by crawling along the spathe, thereby spending lesser time in the inflorescence pollinating female flowers and collecting pollen from male flowers. Whether the fungi use epicuticular waxes or other potential secretions of the papillate cells as nutrients requires further investigation.

In contrast to this negative effect of the fungal layer on plant reproduction, the fungi may also exert some positive effects on plants. Volatile organic compounds released by Cladosporium sphaerospermum act as successful enhancers of plant growth (Li et al., 2019). As C. sphaerospermum is closely related to both fungal species recorded in this study (C. cf. dominicanum, C. halotolerans), and even part of the same phylogenetically defined group (C. sphaerospermum complex; Figure 3), it can be inferred that the investigated fungal species possess similar characteristics. This could consequently have an overarching effect on this particularly large and fast-growing plant.

\section{Acknowledgments}

We thank Alan Fryday (Michigan State University) for linguistic improvement of the manuscript and Robert Schabetsberger (Paris Lodron Universität Salzburg) for providing a picture of $A$. titanum used in Figure $1 \mathrm{~B}$. We would also like to extend our gratitude to the gardeners of the Botanical Garden of the Paris Lodron Universität Salzburg for cultivating the plant, and to Marianne Lauerer (Botanical Garden Bayreuth), Boris Schlumpberger (Herrenhäuser Gärten Hannover), Wolfgang Stuppy (Botanical Garden Bochum), and Patrick Knopf (Botanical Garden Dortmund) for providing useful information regarding the fungus layer visible on the inflorescence of A.titanum. The plant was a generous donation from the Palmengarten Frankfurt (Hilke Steinecke and Stephanie Weber) to the Botanical Garden of the Paris Lodron Universität Salzburg.

\section{References}

Barthlott, W., \& Lobin, W. (Eds.). (1998). Amorphophallus titanum. Akademie der Wissenschaften und der Literatur.

Bensch, K., Braun, U., Groenewald, J. Z., \& Crous, P. W. (2012). The genus Cladosporium. Studies in Mycology, 72, 1-401. https://doi.org/10.3114/sim0003

Bröderbauer, D., Diaz, A., \& Weber, A. (2012). Reconstructing the origin and elaboration of insect-trapping inflorescences in the Araceae. American Journal of Botany, 99, 1666-1679. https://doi.org/10.3732/ajb.1200274

Davis, C. D., Endress, P. K., \& Baum, D. A. (2008). The evolution of floral gigantism. Current Opinion in Plant Biology, 11, 49-57. https://doi.org/10.1016/j.pbi.2007.11.003

El-Morsy, E. M. (2000). Fungi isolated from the endorhizosphere of halophytic plants from the Red Sea Coast of Egypt. Fungal Diversity, 5, 43-54.

Flessa, F., Peršoh, D., \& Rambold, G. (2012). Annuality of Central European deciduous tree leaves delimits community development of epifoliar pigmented fungi. Fungal Ecology, 5, 554-561. https://doi.org/10.1016/j.funeco.2011.12.005

Gandawijaja, D., Idris, S., Nasution, R., Nyman, L. P., \& Arditti, J. (1983). Amorphophallus titanum Becc.: A historical review and some recent observations. Annals of Botany, 51, 269-278. https://doi.org/10.1093/oxfordjournals.aob.a086467

Hardoim, P. R., van Overbeek, L. S., Berg, G., Pirttilä, A. M., Compant, S., Campisano, A., Doring, M., \& Sessitsch, A. (2015). The hidden world within plants: Ecological and evolutionary considerations for defining functioning of microbial endophytes. Microbiology and Molecular Biology Reviews, 79, 293-320. https://doi.org/10.1128/MMBR.00050-14 
Kalyaanamoorthy, S., Minh, B. Q., Wong, T. K. F., von Haeseler, A., \& Jermiin, L. S. (2017). ModelFinder: Fast model selection for accurate phylogenetic estimates. Nature Methods, 14, 587-589. https://doi.org/10.1038/nmeth.4285

Latz, M. A. C., Jensen, B., Collinge, D. B., \& Jørgensen, H. J. L. (2018). Endophytic fungi as biocontrol agents: Elucidating mechanisms in disease suppression. Plant Ecology \& Diversity, 11, 555-567. https://doi.org/10.1080/17550874.2018.1534146

Li, Z., Janisiewicz, W. J., Liu, Z., Callahan, A. M., Evans, B. E., Jurick, W. M., II, \& Dardick, C. D. (2019). Exposure in vitro to an environmentally isolated strain TC09 of Cladosporium sphaerospermum triggers plant growth promotion, early flowering, and fruit yield increase. Frontiers in Plant Science, 9, Article 1959. https://doi.org/10.3389/fpls.2018.01959

Napp-Zinn, K., \& Scheferhoff, R. (1998). Anatomische Untersuchung der Spatha [Comparative anatomical investigations in the spathe of Amorphophallus titanum]. In W. Barthlott, \& W. Lobin (Eds.), Amorphophallus titanum (pp. 81-98). Akademie der Wissenschaften und der Literatur.

Rambaut, A. (2014). FigTree version 1.4.3 [Computer software]. http://tree.bio.ed.ac.uk/software/figtree/

Ronquist, F., \& Huelsenbeck, J. P. (2003). MrBayes 3: Bayesian phylogenetic inference under mixed models. Bioinformatics, 19, 1572-1574. https://doi.org/10.1093/bioinformatics/btg180

Ruprecht, U., Fernández-Mendoza, F., Türk, R., \& Fryday, A. (2020). High levels of endemism and local differentiation in the fungal and algal symbionts of saxicolous lecideoid lichens along a latitudinal gradient in southern South America. Lichenologist, 52, 287-303. https://doi.org/10.1017/S0024282920000225

Sayyad, S., \& Mulani, R. M. (2016). Endophytic fungal diversity in corms of Amorphophallus sylvaticus (Roxb.) Kunth. International Journal of Scientific Engineering and Research, 4 , 32-34.

Stępniewska, Z., \& Kuźniar, A. (2013). Endophytic microorganisms - Promising applications in bioremediation of greenhouse gases. Applied Microbiology and Biotechnology, 97, 9589-9596. https://doi.org/10.1007/s00253-013-5235-9

Trifinopoulos, J., Nguyen, L.-T., von Haeseler, A., \& Minh, B. Q. (2016). W-IQ-TREE: A fast online phylogenetic tool for maximum likelihood analysis. Nucleic Acids Research, 44(W1), W232-W235. https://doi.org/10.1093/nar/gkw256

Wani, Z. A., Ashraf, N., Mohiuddin, T., \& Riyaz-Ul-Hassan, S. (2015). Plant-endophyte symbiosis, an ecological perspective. Applied Microbiology and Biotechnology, 99, 2955-2965. https://doi.org/10.1007/s00253-015-6487-3

White, T. J., Bruns, T. D., Lee, S. B., \& Taylor, J. W. (1990). Amplification and direct sequencing of fungal ribosomal genes for phylogenies. In M. A. Innis, D. H. Gelfand, J. J. Sninsky, \& T. J. White (Eds.), PCR protocols. A guide to methods and applications (pp. 315-322). Academic Press. https://doi.org/10.1016/B978-0-12-372180-8.50042-1

Zalar, P., de Hoog, G. S., Schroers, H.-J., Crous, P. W., Groenewald, J. Z., \& Gunde-Cimerman, N. (2007). Phylogeny and ecology of the ubiquitous saprobe Cladosporium sphaerospermum, with descriptions of seven new species from hypersaline environments. Studies in Mycology, 58, 157-183.

https://doi.org/10.3114/sim.2007.58.06 